\title{
INTRODUÇÃO A UMA CRÍTICA DA MODERNIDADE COMO CONCEITO SOCIOLÓGICO
}

\author{
João Feres Junior ${ }^{1}$
}

\begin{abstract}
RESUMO
0 presente artigo empresta a metodologia da história conceitual assim como os achados substantivos do principal ensaio de história conceitual sobre o conceito de modernidade, de autoria de Hans Ulrich Gumbrecht, para articular uma crítica ao uso contemporâneo do conceito de "modernidade" por parte da sociologia, com ênfase para a sociologia brasileira. Mostro que dois significados fundamentais historicamente associados ao conceito se encontram replicados no material sociológico de maneira não reflexiva: o de moderno como oposto ao tradicional em um esquema temporal evolutivo linear, e o de modernidade no sentido de período transitório que se opõe a eterno inamovível. A falta de reflexividade crítica acerca do conceito e a pletora de significados a ele atribuídos conduzem a um resultado contrário ao que se espera de um conceito "analítico". Em vez de clareza, temos confusão e a importação implícita e universalização de grandes narrativas européias etnocêntricas, que a sociologia usa como medida para a avaliação de sociedades não-ocidentais.
\end{abstract}

Palavras-chave: Modernidade. História conceitual. Sociologia. Temporalidade. Max Weber.

\footnotetext{
${ }^{1}$ Pesquisador e professor de ciência política junto ao Instituto de Estudos Sociais e Políticos (IESPUERJ) e professor de ciência política do Centro de Ciências Jurídicas e Políticas da UNIRIO. É autor de Histoire du concept d'Amérique Latine aux États-Unis (L'harmattan, 2010) e Teoria política contemporânea: uma introdução (Campus-Elsevier, 2010).End. Eletrônico: jferes@iesp.uerj.br
} 


\section{INTRODUCTION TO A CRITIQUE OF MODERNITY AS A SOCIOLOGICAL CONCEPT}

\section{Abstract}

This article borrows the methodological framework from the conceptual history, as well as some of the substantive findings from the principal essay of conceptual history on the concept of modernity by Hans Ulrich Gumbrecht, to criticize the present-day use of the concept of modernity by sociology, paying special attention to the sociology produced in Brazil. I demonstrate that two fundamental meanings historically associated with the concept of modernity are also present in the sociological material although in a rather non-reflexive manner. They are: modern as something opposed to traditional within a scheme of linear temporal evolution and modernity as a transitional period as opposed to that which is eternal and immutable. The lack of critical reflexivity on the concept combined with the plethora of meanings attributed to it lead to a situation entirely opposed to what one would expect from an analytical concept. Instead of clarity, we have confusion and the implicit importation and universalization of major ethnocentric European narratives, which sociology uses as a sort of measurement to evaluate non-European societies.

Keywords: Modernity. Conceptual history. Sociology. Temporality. Max Weber.

$\mathrm{N}$ Reunião Anual da ANPOCS de 2004, estava eu participando em uma discussão em uma mesa com o professor Carlos Hasenbalg e outras pessoas, quando esse grande sociólogo argentino, em um momento de descontração, proferiu um chiste mais ou menos assim: "Após dar uma olhada no programa da ANPOCS 2004, decidi que no ano que vem, minha última ANPOCS², vou apresentar um trabalho com o título 'Dilemas da Modernidade múltipla, global, religiosa, incompleta, periférica radicalizada, singular, hiper, como liberdade, latinoamericana e brasileira'."

A brincadeira de Hasenbalg me soou muito espirituosa. A princípio, atribuí sua reação a uma possível rejeição, por parte de alguém mais acostumado a trabalhar com a interface entre teoria e empiria, dos trabalhos mais puramente teóricos de ciências sociais, aqueles que geralmente se propõem a discutir as

\footnotetext{
${ }^{2}$ Hasenbalg falava assim, pois pretendia se aposentar em 2006 e mudar-se para a Argentina. Coisa que de fato fez.
} 
características sociológicas do Zeitgeist. Mas logo percebi que a observação continha uma verdade mais profunda. Há muito que noto uma grande cacofonia em relação ao uso do conceito de moderno e modernidade por parte de cientistas sociais, aqui no Brasil e alhures. A lista acima não corresponde exatamente ao que meu colega disse naquele momento, mas é sim uma coletânea fidedigna dos adjetivos que acompanham o substantivo modernidade nos vários trabalhos apresentados no Encontro da ANPOCS de 2004.

Nesse artigo, procuro refletir sobre esse estado de coisas. Com o auxílio da história conceitual, principalmente do trabalho de Hans Ulrich Gumbrecht sobre a história do conceito de modernidade, identificarei parte da pletora de significados que foram associados aos termos moderno e modernidade, para tirar algumas lições úteis acerca de seu uso, no presente, como ferramenta analítica das ciências sociais. Em um segundo momento, discutirei a especificidade do uso hifenizado, ou adjetivado, do conceito de modernidade para a reflexão sobre a sociedade brasileira, chamando atenção para alguns de seus pressupostos e conseqüências.

\section{A LONGa História dA MODERNIDADE}

Ao adotar a história conceitual como disciplina auxiliar nesse trabalho pretendo subverter em parte o método sociológico de conceituação, que na maioria das vezes opera através do achatamento, quando não da rejeição completa, do aspecto temporal e, portanto, contingente e instável do significado dos conceitos. A sociologia reclama o espaço epistêmico da sincronia, des-historiza os conceitos. Façamos o movimento contrário.

Parte significativa da reflexão acadêmica sobre o conceito de modernidade foi produzida na Alemanha. Sobre o tema, temos trabalhos paradigmáticos como os de Karl Löwith (1949) e Hans Blumenberg (1974), e o debate que aí se originou. Posteriormente, Reinhart Koselleck também contribuiu para o tema, com sua teoria sobre a mudança das linguagens políticas na Alemanha do século XVIII e XIX, na qual figura proeminentemente o conceito de Sattelzeit (período de transição para a modernidade) (KOSELLECK, 1985; LEHMANN; RICHTER, 1996), e com a Geschichtliche Grundbegriffe, um léxico de conceitos históricos e sociais de 9 volumes do qual o autor foi um dos editores (BRUNNER; CONZE; KOSELLECK, 1972). Sobre a história do conceito de modernidade/moderno mais especificamente há pelo menos cinco textos significativos, dois de Hans Robert Jauss $(1965,1971)$, cobrindo aspectos ligados à estética e à arte, o ensaio de Jost 
Schneider (1971) lidando basicamente com literatura, o verbete de Fritz Martini (1965) para o Reallexikon der deutschen Literaturgeschichte focado nos aspectos filosóficos do conceito, e o verbete de Hans Ulrich Gumbrecht $(1978)^{3}$ para a Geschichtliche Grundbegriffe, de longe o ensaio mais completo sobre o tópico dessa coleção. Por essa razão, esse último trabalho vai ser a principal referência dessa seção de apresentação.

Gumbrecht identifica três significados básicos que o termo "moderno" assumiu durante sua história:

o primeiro significado é simplesmente "presente", em oposição a "anterior" ou "prévio", e foi usado dentro de tradições institucionalizadas onde tendências se sucedem temporalmente.

o segundo significado é de "novo" e oposição a "velho": nesse caso já se tem o embrião de uma consciência epocal onde moderno define um espaço de experiência presente que se quer distinto do passado. Esse uso geralmente está ligado a um esquema temporal mais ou menos explícito de hierarquização das eras, ou seja, é fortemente valorativo.

Por fim temos o significado de "período transitório", em oposição ao eterno. Nessa versão, moderno designa um presente que é experimentado como fluxo temporal contínuo e veloz que, como tal, só pode ser oposto ao eterno, qual inamovível.

Para além dessa análise da estrutura semântica histórica do conceito de moderno/modernidade, o autor oferece uma série de exemplos históricos reveladores. Vamos a alguns deles.

0 primeiro uso do termo latino "modernus" de que se tem notícia encontra-se na Epistolae pontificum de Gelasius 4 , do ano 494 da era cristã. Nela, esse papa de origem africana qualifica os decretos do Concílio de Calcedônia como admonitiones modernae, em oposição às regulis antiquis ainda em vigor. Em 507, Cassiodorus 5 emprega a palavra em uma carta já com o sentido de oposição

\footnotetext{
30 ensaio de Gumbrecht apareceu originalmente como um verbete na Geschichtliche Grundbegriffe. No presente artigo as referências são da tradução do texto para o inglês publicada no volume Making sense in life and literature (GUMBRECHT, 1992).

${ }^{4}$ Gelasius I, papa de 492 a 496. 0 terceiro papa de origem africana na história da igreja.

${ }^{5}$ Flavius Magnus Aurelius Cassiodorus Senator (ca 484/490 - ca585), conhecido simplesmente como Cassiodorus, foi político romano e escritor de grande prestígio e serviu a Teodorico 0 Grande, rei dos Ostrogodos.
} 
entre épocas. 0 autor denominava-se antiquorum diligentissimus imitator e defendia o modelo de grandeza romana como objeto de emulação por parte do império gótico, passando assim a receber também a alcunha de modernorum nobilissimus institutor. Há outros exemplos do uso do termo nesse sentido durante a alta idade média. Por exemplo, o "império universal" de Carlos Magno ${ }^{6}$ foi batizado de saeculum modernum e, já naquele período, Boethius ${ }^{7}$ passou a ser conhecido como o fundador da literatura moderna. Como nota Gumbrecht, nesses exemplos do primeiro milênio o termo não está inscrito em uma teoria valorativa da história.

Isso se altera já no século XI. Durante a Querela das Investiduras, modernitas (modernidade) passa a designar o período que se estende até 0 presente e que se distanciou dos preceitos dos padres fundadores da Igreja, ou seja, adquire um sentido negativo, de oposição a uma época passada identificável.

Durante 0 renascimento, a valoração negativa do presente é invertida: 0 passado continua a ser objeto de admiração, mas sua excelência agora pode ser superada no presente. Nada mais significativo dessa nova consciência epocal do que a imagem cunhada por Bernando de Chartres ${ }^{8}$ dos moderni como anões em cima dos ombros dos gigantes da antiguidade e, portanto, capazes de ver ainda mais longe que os próprios gigantes.

Walter Map ${ }^{9}$, em seu De nugis curialium, escreve por volta do final do século XII: "saeculis sua discplicunt modernitas" (todas as eras do passado entendiam a si próprias como modernidades). 0 relativismo de Map antecipa o sentido dominante que o termo adquiriu no século XIII, quando foi usado frequentemente na oposição antiqui versus moderni, simplesmente para designar escolas filosóficas rivais (aristotelismo = via moderna, ou o nominalismo de Ockham), independentemente de qualquer teoria epocal.

Durante o renascimento a consciência histórica começou a se moldar segundo a narrativa paradigmática de seqüência epocal: esplendor da antiguidade clássica, decadência da era cristã e renascimento. Mas essa concepção ainda

\footnotetext{
${ }^{6}$ Carlos Magno (ca. 742 or 747 - 814), rei dos francos e lombardos, e imperador do "Ocidente". ${ }^{7}$ Anicius Manlius Severinus Boethius (480 - 524 or 525), filósofo cristão nascido em Roma e que serviu à monarquia ostrogótica.

${ }^{8}$ Bernard de Chartres (Bernardus Carnotensis), filósofo francês do século XII.

${ }^{9}$ Walter Map ( 1137-1209), escritor de origem galesa.
} 
era cíclica e eminentemente voltada para o passado, como modelo básico de compreensão da história.

Somente com o iluminismo francês, ou mais especificamente durante a Querelle dês anciens et dês modernes (1680), o sentimento definitivo de superioridade do presente frente ao passado clássico foi claramente enunciado dentro de uma concepção temporal evolutiva e linear, orientada pelo conceito da perfectibilidade humana. Nesse esquema, a antiguidade clássica passa a ser a infância da humanidade, a renascença sua adolescência e a modernidade sua maturidade. Contudo, vale lembrar que, a despeito dessa inovação do iluminismo, seu principal documento, a Encyclopaedie, ainda não contém uma definição epocal coesa de modernidade. 0 verbete desse termo atribui o nascimento da literatura moderna a Boethius, da moderna astronomia a Copérnico e o da física moderna a Newton, ou seja, não há uma narrativa coesa das características essenciais dessa época específica.

0 iluminismo francês foi fortemente neo-clássico, ou seja, a antiguidade clássica foi sua referência par excelence. Sua concepção temporal, ainda que se abrisse para o futuro através da idéia de perfectibilidade, ainda olhava para 0 passado como modelo normativo. Segundo Gumbrecht, foi só com o romantismo alemão que o futuro passa a ser o ponto de referência da consciência histórica. Isso se torna possível através da valorização da reflexão histórica, que produz uma consciência da consciência epocal, por assim dizer. Como declara Wilhelm von Humboldt (apud GUMBRECHT, 1978, p. 90): "os antigos eram meramente o que eram. Nós já sabemos o que somos e olhamos para além. Através da reflexão, nos transformamos em uma pessoa dupla". Concepção muito similar encontra-se, por exemplo, em Hegel (1944) e em Hegel, Miller e Findlay (1977).

É só a partir da década de 1830 que o termo modernidade passa a ser usado no sentido de tempo presente transitório, que está destinado a ser superado por um futuro. Baudelaire declara que "La modernité, c'est le transitoire, le fugitif, le contingent". É nesse sentido que esse conceito é articulado por Marx. Na Crítica à Filosofia do Direito de Hegel (MARX; O'MALLEY, 1970), o autor defende que o surgimento do regime representativo constitucional marca o advento do Estado moderno, em contraposição ao Estado medieval, onde o dualismo Estado/sociedade era implícito. Em seus textos subseqüentes Marx iria explicitar a transitoriedade dessa modernidade burguesa e prever sua superação revolucionária (MARX; ENGELS; BEER, 1987; MARX; et al., 1970). 
A partir do século XIX, o conceito de modernidade sofre também um processo semântico que não foi identificado seja por Gumbrecht ou Koselleck em seus trabalhos. Koselleck enumera quatro processos histórico-semânticos que caracterizariam a modernidade, ou seja, descreve quatro processos pelos quais os conceitos sociais e políticos passariam durante o período de transição para a modernidade. São eles: temporalização, ideologização, politização e democratização. Os dois primeiros dizem respeito mais estritamente à semântica dos conceitos. A temporalização acontece quando o conceito passa a integrar grandes teorias da história, ou ele mesmo introjeta grandes narrativas em seu arco semântico. A ideologização diz respeito à crescente generalização sofrida por alguns conceitos, que passam a representar não objetos particulares (ex: histórias, direitos, liberdades etc.), mas entidades totais e universais (história, direito, liberdade etc.). Os dois últimos estão ligados a processos sócio-históricos de utilização do vocabulário. A politização corresponde ao uso de conceitos como instrumentos de debate público, inclusive para desacreditar, humilhar e desmoralizar adversários; e a democratização é o processo pelo qual os conceitos sociais e políticos passam a ser utilizados por um número cada vez maior de pessoas.

Em seu estudo do conceito de civilização, Pim den Bôer (2001) identificou um outro processo batizado por ele de nacionalização. Segundo o autor, ele corresponderia à incorporação de conceitos outrora generalistas e abstratos a ideologias nacionalistas. Em Wagner, por exemplo, notamos esse processo operando, ainda que de forma invertida, pois a modernidade é identificada como vulgaridade democrática, sentimento de ruptura com o passado radical, influência judaica e, portanto, ameaça à nação alemã.

A despeito de uma tendência na Alemanha de se rejeitar a modernidade por seu caráter anti-nacional, algo que também se deu na Espanha, a palavra tornouse parte do vocabulário corrente de todas línguas européias com o significado, segundo Gumbrecht, de presente como passado de um futuro, ou seja, o terceiro significado, aquele de período transitório. Contudo, para além dessa constatação da ordem da semântica estrutural, Gumbrecht (1992, p. 102) conclui: "Quando os princípios dos vários arautos do moderno são listados lado a lado, temos um amplo espectro de doutrinas artísticas, filosóficas e políticas, e não uma teoria unificada."

Desse rápido panorama da história do conceito de moderno/modernidade retiramos algumas lições que podem nos ajudar a compreender a cacofonia do conceito de modernidade nas ciências sociais brasileiras do presente. 
A cacofonia também se verifica no material histórico. Não há propriamente uma evolução semântica histórica de uma definição, um desenvolvimento linear da consciência temporal, mas a superposição de três tipos de definições básicas com conteúdos, limites e horizontes epocais, e força valorativa muito variados. Ademais, quanto mais nos aproximamos do presente, a cacofonia parece aumentar.

A tipologia semântica apresentada por Gumbrecht de cara nos permite fazer uma avaliação, ainda que muito geral, do conjunto de usos do termo moderno/modernidade nas ciências sociais tupiniquins. Não se trata aqui do primeiro sentido, o de atual, que se opõe a anterior, pois tal sentido pertence a uma concepção temporal muito simples e cíclica e, portanto, de parco poder valorativo. 0 mesmo não se pode dizer dos outros dois sentidos, pois, a despeito de sua profusão semântica, os usos aqui referidos parecem partilhar de aspectos estruturais dos dois outros significados identificados por Gumbrecht, a saber, o segundo, aquele que opõe o moderno, qual época, ao velho dentro de um esquema temporal evolutivo linear, e o terceiro, o sentido de período transitório que se opõe ao eterno inamovível.

A despeito das inúmeras críticas feitas às várias teorias da modernização, sejam elas weberianas ou marxistas, a partir da década de 1960, o sentido de evolucionismo linear permanece. Esse evolucionismo é explicitado pela hifenização, que denota a falta: as modernidades hifenizadas são aquelas que ainda não se tornaram modernidades plenas, mas aspiram a isso. Essa orientação para o futuro, mesmo que muitas vezes implícita, também pode ser lida como um índice do terceiro sentido, o de transitoriedade: 0 moderno é entendido como o estado eterno, ou seja, o modelo ao qual todas as sociedades aspiram. Tal qual Francis Fukuyama (1992), uma parte significativa da sociologia do presente, consciente ou inconscientemente, vê na democracia liberal capitalista o horizonte possível de desenvolvimento da sociabilidade humana. Daí que todas as sociedades que ainda não chegaram lá devem ser descritas por essas categorias hifenizadas da modernidade ainda não acabada.

\section{Modernidade E OS CLÁSSICOS DA SOCIOLOGIA}

Vejamos agora, de maneira mais direta, como opera a redução, padronização e achatamento histórico no ato da conceituação sociológica do moderno. Usaremos como exemplo os dois paradigmas mais influentes das ciências sociais no século XX, o marxismo e o weberianismo. 0 primeiro, muito 
influente durante quase todo o século, hoje se encontra moribundo. Como já dissemos, em Marx está presente um conceito de modernidade representada pelo Estado burguês e pelo modo de produção capitalista, como período de transição para uma época futura, "pós-moderna": a sociedade comunista.

Marx adota uma periodização da história em quatro estágios: antiguidade, feudalismo (Idade Média), modernidade burguesa e sociedade comunista (MARX; SITTON, 2010). Esse esquema funciona também como padrão de avaliação de outras sociedades. Isso lhe permite, por exemplo, justificar o colonialismo inglês na Índia e China, pois esse, segundo sua maneira de ver as coisas, iria transformar essas sociedades despóticas marcadas pelo modo de produção asiático em sociedades capitalistas e, portanto, potencialmente revolucionarias (MARX; AVINERI, 1968).

Os marxistas não raro são vítimas de um evolucionismo similar. Florestan Fernandes (1965), para citar um exemplo que nos é mais próximo, interpreta 0 preconceito de raça no Brasil capitalista como um resquício da ordem escravocrata e, portanto, fadado ao desaparecimento por ser desprovido de função na ordem social desse modo de produção. É claro que o simples fato de um autor ser identificado como marxista não necessariamente redunda na incorporação acrítica dessa concepção linear de modernização. Fato é que poucos explicitaram alguma consciência crítica em relação a esse problema, exceção feita à teoria de dependência e alguns de seus seguidores (CARDOSO; FALETTO, 1969; FRANK, 1967)

Sem dúvida alguma, as teorias mais influentes e operantes das ciências sociais brasileiras e mundiais do presente são de alguma maneira relacionadas ao paradigma weberiano. Em sua tipologia da ação, Weber opôs as formas racionais de ação (Zweckrational e Wertrational), identificadas por ele com a modernidade, à ação denominada tradicional. Na tipologia das formas de dominação (Herrschaft), o caráter temporal é ainda mais explícito, pois a dominação racional-legal corresponde exatamente ao regime constitucional identificado com a modernidade européia, enquanto que a dominação tradicional descreve todas as outras práticas, de forma explicitamente contraconceitual (WEBER, 1968). A sociologia de Weber, principalmente na leitura feita a partir da academia norteamericana, promove um enxugamento radical do campo semântico do conceito de modernidade (uma lipoaspiração), um expurgo da história, propriamente dita. 
Modernidade ou moderno pode então ser definido como um modo de proceder, uma modalidade de dominação, uma forma de governo.

É claro que a história não é completamente expelida. Ela ainda está presente na miríade de exemplos de textos que adornam trabalhos como Economia e Sociedade (WEBER, 1968) e mesmo em obras como A Ética protestante e o espirito do capitalismo (WEBER; PARSONS; TAWNEY, 1950). É na Ética Protestante que a teoria da modernidade de Weber se apresenta de maneira mais completa. 0 texto explica o domínio da racionalidade instrumental na sociedade moderna como um produto da secularização da ética protestante puritana de controle do corpo e domínio do mundo exterior. Aqui temos uma teoria da gênese histórica da modernidade, de ética de uma minoria religiosa a espírito de uma época. Mas é também na Ética Protestante que Weber mostra uma forte influência de Nietzsche, ao pintar o quadro cinzento do homem moderno dominado pela racionalidade instrumental e, portanto, incapaz de eleger valores substantivos que possam dar sentido à sua vida: a gaiola de ferro, na tradução equivocada de Talcott Parsons.

Poderíamos escrever volumes sobre a complexidade, tensões e contradições da concepção de modernidade em Weber. Infelizmente, para a reflexão sociológica, 0 weberianismo chega aos nossos dias como uma teoria empobrecida, muitas vezes filtrada pela leitura dele feita pela poderosa e influente sociologia norte-americana. Nessa tradição acadêmica, a compressão semântica é máxima ${ }^{10}$. A ambivalência e mesmo o pessimismo de Weber em relação à modernidade édescartado, ou melhor, substituído por uma visão otimista do progresso material e moral do ocidente moderno. Essa leitura já é clara na aplicação que Parsons faz de suas patternvariables (PARSONS, 1964, 1966). Mas em lugar algum esse weberianismo raquítico refulgiu com tanta intensidade como na teoria da modernização. Nos textos de seus arautos, o moderno/modernidade se define por uma versão simplificada e completamente desistoricizada da teoria de Weber: protestantismo $=$ racionalidade $=$ desenvolvimento material e moral $=$ modernidade. Acoplado a isso, temos uma geografia onde a modernidade é igualada ao Ocidente, às vezes somente ao Ocidente protestante, e muitas vezes explicitamente aos EUA (FERES JÚNIOR, 2005). A teoria da modernização desapareceu como denominação, após severas críticas desfechadas contra ela tanto do interior do mundo acadêmico norteamericano como de fora. Infelizmente, seus pressupostos continuam presentes e

\footnotetext{
${ }^{10}$ De maneira análoga, o perspectivismo nietzscheano de Weber no tocante à epistemologia das ciências sociais é também descartado. Para uma defesa dessa interpretação nietzscheana de Weber, ver Palonen $(1998,1999,2001)$.
} 
operantes nas ciências sociais do presente, muitas vezes através do uso do próprio conceito de modernidade. Uma imagem de ocidente idealizada é tomada, muitas vezes de maneira não-reflexiva e mesmo implícita, como modelo contra o qual sociedades reais devem ser medidas. 0 conceito de modernidade funciona como a régua e as hifenizações como gradações da medida.

\section{Conclusão}

Voltemos à cacofonia inicial, a dos trabalhos da ANPOCS 2004. Como já disse, uma característica comum ao emprego do conceito de modernidade para refletir sobre a sociedade brasileira é sua hifenização. Nesses usos, a adjetivação do conceito tem a função semântica de diminuir seu escopo, definir uma deficiência, uma falta da modernidade propriamente dita. Aqui identificamos uma dupla falha: uma idealização simplificadora seguida de uma tentativa de constituição de uma categoria analítica que corresponde à negação parcial dessa idealização (o quase-moderno). Quer-se explicar o que é (o Brasil), a partir daquilo que lhe falta em relação a um padrão ideal (o moderno).

Mas isso não é tudo. Pior do que produzir uma análise baseada em um esquema conceitual pobre é a ingenuidade de se apropriar de um conceito semanticamente tão adiposo como modernidade, reduzindo-o a uma fórmula simples do tipo: modernidade é... Basta olharmos para o conjunto de tentativas dessa natureza para notarmos a volta da cacofonia em grande estilo: Seria ela o advento do capitalismo ou seu último estágio, a economia de mercado ou a intervenção estatal na economia, ou ainda, o advento do Estado nacional, da esfera pública, da sociedade de massas, da colonização da política pela economia, do surgimento do self-pontual etc? Ora, não só o significado de modernidade é contestado, como também sua aplicação: estamos na era moderna ou na pósmodernidade?

Ademais, o esforço de se apagar a complexidade semântica do conceito redunda não em maior precisão conceitual, como muitos pretendem, mas em um efeito ideológico, no sentido que o termo tem de ocultação. Dessa maneira, elementos semânticos continuam presentes, sem serem explicitados e, portanto, sujeitos à crítica. Quais seriam esses elementos? Aqui me aventuro a identificar alguns:

1) o conceito de modernidade carrega associações com práticas culturais, valores políticos e estéticos específicos (TAYLOR, 1989), que através do expurgo 
semântico são universalizados e naturalizados. Assim, particularismos europeus ou norte-americanos são tomados como modelo de racionalidade e de modernidade.

2) a sociologização do conceito impõe um ideal de moderno como medida para sociedades históricas particulares. Assim, promove-se a glorificação implícita das sociedades de fato que representam o modelo (Ocidente, EUA, Europa) e condena-se à incapacidade histórica as hifenizadas.

3) por fim, apaga-se o fato de que os processos de modernização no mundo todo sacramentam padrões estéticos e raciais altamente excludentes e danosos para aquelas sociedades que por razões físicas não podem parecer-se com os modelos de modernidade. A indústria de cosméticos para o embranquecimento da pele na Índia ou mesmo o surto de apresentadoras de programas infantis louras no Brasil da década de 1980 atestam, de maneira um pouco jocosa, essa triste realidade.

A análise da história do conceito moderno/modernidade nos mostra que esse foi usado de muitas maneiras, com muitos significados distintos e para muitos propósitos. Além de constatar a dificuldade, senão ilusão, de reduzir seu campo semântico a golpes de marreta, precisamos nos perguntar para que nos serve esse conceito. Qual o seu real poder explicativo? Será que nos ajuda ou atrapalha a explicar os fenômenos sociais que nos interessam? Espero que esse ensaio tenha contribuído para pelo menos começarmos a responder essas questões.

\section{REFERÊNCIAS}

BLUMENBERG, Hans. On a lineage of the idea of progress. Social Research, New York, v. 41, n. 1, p. 5-27, 1974.

BÔER, Pim den. Civilisation (beschaving). Amsterdam: Amsterdam University Press, 2001.

BRUNNER, Otto; CONZE, Werner; KOSELLECK, Reinhart. Geschichtliche grundbegriffe: historisches lexikon zur politisch-sozialen sprache in Deutschland. Stuttgart: Klett, 1972.

FERNANDES, Florestan. A Integração do Negro na Sociedade de Classes. São Paulo: Dominus, 1965.

CARDOSO, Fernando Henrique; FALETTO, Enzo. Dependencia y desarrollo en américa latina; ensayo de interpretación sociológica. México: Siglo Veintiuno, 1969. 
FERES JÚNIOR, João. A história do conceito de latin america nos Estados Unidos. Bauru, São Paulo: Edusc, 2005.

FRANK, Andre Gunder. Capitalism and underdevelopment in latin america: historical studies of Chile and Brazil. New York: Monthly Review Press, 1967.

FUKUYAMA, Francis. The end of history and the last man. New York: Avon Books, 1992.

GUMBRECHT, Hans Ulrich. Modern, modernität, moderne. In: BRUNER, Otto; CONZE, Werner; KOSELLEK, Reinhart. Geschichtliche grundbegriffe: historisches lexikon zur politisch-sozialen sprache in Deutschland, Vol. 4, Stuttgart: KlettCotta, 1978. p. 93-131.

GUMBRECHT, Hans Ulrich. Making Sense in Life and Literature, Theory and History of Literature. Minneapolis: University of Minnesota Press, 1992.

HEGEL, Georg Wilhelm Friedrich. The philosophy of bistory. New York: Willey, 1944.

HEGEL, Georg WilhelmFriedrich;MILLER, ArnoldV.;FINDLAY,J.N.Phenomenology of spirit. Oxford: Oxford University Press, 1977.

JAUSS, Hans Robert. Literarische tradition und gegenwärtiges bewußtsein der modernität. wortgeschichtliche betrachtungen. In: STEFFEN, Hans. Aspekte der modernität, Göttingen: Vandenhoeck \& Ruprecht, 1965. p. 150-197.

JAUSS, Hans Robert. Antiqui/Moderni (Querelle Des Anciens Et Des Modernes). In: RITTER, J.; GRÜNDER, K (Ed.). Historisches Wörterbuch Der Philosophie, Basel: Schwabe. Vol. 1, 1971. p. 410-414.

KOSELLECK, Reinhart. Futures past: on the semantics of historical time. Cambridge: The Mit Press. 1985.

LEHMANN, Hartmut; RICHTER, Melvin (Ed.). The meaning of historical terms and concepts: new studies on begriffgeschichte. Washington: German Historical Institute, 1996. Occasional Paper, v. 15.

LÖWITH, Karl. Meaning in history. Chicago: The University Of Chicago Press, 1949 .

MARTINI, Fritz. Modern, die moderne. In: MERKER, P.; STAMMLER, W.; KOHLSCHMIDT, W. Reallexikon der deutschen literaturgeschichte. Berlin: De Gruyter. 1965. 
MARX, Karl; AVINERI, Shlomo. Karl Marx on colonialism and modernization; bis despatches [sic] and other writings on China, India, Mexico, the middle east and north Africa. Garden City, N.Y.: Doubleday, 1968.

MARX, Karl; ENGELS, Friedrich; BEER, Samuel Hutchison. The communist manifesto. Arlington Heights: H. Davidson, 1987.

MARX, Karl; ENGELS, Friedrich; LENIN, Vladimir Ilyich; CZOBEL, E. Critique of the gotha programme. New York: International Publishers, 1970.

MARX, Karl; O'MALLEY, Joseph J. Critique of Hegel's 'philosophy of right'. Cambridge: University Press, 1970.

MARX, Karl; SITTON, John F. Marx today : selected works and recent debates. New York: Palgrave Macmillan, 2010.

PALONEN, Kari. Das Webersche moment: zur kontingenz des politischen. Opladen: Westdeutscher Verlag, 1998.

. Max Weber's reconceptualization of freedom. Political Theory, Beverly Hills, v. 27, n. 4, p. 523-544, 1999.

. Was Max Weber a 'nationalist': a study in the rhetoric of conceptual change. Max Weber Studies, London, v. 1, n. 2, p. 196-213, 2001.

PARSONS, Talcott. The Social System. New York: Free Press, 1964.

Societies: evolutionary and comparative perspectives. Englewood Cliffs: Prentice-Hall, 1966.

SCHNEIDER, Jost. Ein beitrag zu dem problem der 'modernität'. Der Deutschunterricht, Stuttgart, v. 23, n. 6, p. 58-67, 1971.

TAYLOR, Charles. Sources of the self: the making of the modern identity. Cambridge: Harvard University Press, 1989.

WEBER, Max; PARSONS, Talcott; TAWNEY, R. H. The protestant ethic and the spirit of capitalism. New York: Scribner's, 1950.

WEBER, Max. Economy and Society; an Outline of Interpretive Sociology. New York,: Bedminster Press, 1968. 